\title{
Nutritional Requirements of an Aspergillus niger Mutant for Citric Acid Production
}

\author{
BY B. HELEN TRUMPY AND NANCY F. MILLIS \\ School of Bacteriology, University of Melbourne, Australia
}

(Received 12 June 1962)

\begin{abstract}
SUMMARY
The nutritional requirements for high conversion of sugar to citric acid in shaken flask fermentations were investigated for the mutant strain 72-44 of Aspergillus niger. Single variable and factorial experiments were used to determine the effects of nitrogen, phosphorus, magnesium, manganese, copper, zinc and iron on the yield of citric acid. When $2 \%(\mathrm{v} / \mathrm{v})$ peanut oil was added to the fermentation media it markedly improved the yield of citric acid. Two media were devised which yielded on average 10-10.5 g. anhydrous citric acid from $14 \mathrm{~g}$. sugar, with occasional yields as high as $13 \mathrm{~g}$. Both media contained $2 \%(\mathrm{v} / \mathrm{v})$ peanut oil and the following trace metals (mg./l.): $\mathrm{Fe}^{2+} 2 \cdot 0 ; \mathrm{Cu}^{2+} 0 \cdot 3 ; \mathrm{Zn}^{2+} 0 \cdot 1$. In medium $\mathrm{A}$ the major nutrients were (g./l.): ion-exchange purified cane sugar, 140; $\mathrm{KH}_{2} \mathrm{PO}_{4}, 1.0 ; \mathrm{MgSO}_{4} .7 \mathrm{H}_{2} \mathrm{O}, 0.25 ; \mathrm{NH}_{4} \mathrm{NO}_{3}, 1.87$; and in medium $\mathrm{B}$ (g./l.): ion-exchange purified cane sugar, $140 ; \mathrm{KH}_{2} \mathrm{PO}_{4}, 0.3 ; \mathrm{MgSO}_{4} .7 \mathrm{H}_{2} \mathrm{O}$, $0 \cdot 15 ; \mathrm{NH}_{4} \mathrm{NO}_{3}, 1 \cdot 4$. Interactions were found between: zinc and iron, nitrogen and iron, nitrogen and phosphorus. The implications of these findings for the fermentation of crude sugar substrates in citric acid production are discussed.
\end{abstract}

\section{INTRODUCTION}

Conditions which control citric acid accumulation in fermentation with Aspergillus niger have been reviewed by Foster (1949), Johnson (1954) and Perlman \& Sih (1960). Published work shows that there are considerable variations in the conditions which different workers have found to be optimal for citric acid accumulation, that the mould strain is of great importance and that the yield of citric acid from carbohydrate metabolized by $A$. niger is extremely sensitive to trace metals, particularly under submerged culture conditions. Even under supposedly identical, ideal conditions, the yield of citric acid is variable. Previously, characterization of the cultural conditions which lead to high yields of citric acid has been based on experiments where single components of the medium have been varied and the best concentrations determined. The difficulty with this experimental design is that frequently the best concentration of the component under test is dependent on the concentrations of other components in the medium. An example of this was found by Shu \& Johnson (1948) who showed with strain 72-4, of $A$. niger that the optimal concentration of $\mathrm{KH}_{2} \mathrm{PO}_{4}$ was twice as great when trace metals were limiting as when trace metals were not limiting.

Our laboratory has been attempting to define the conditions which will allow the production of citric acid by Aspergillus niger in submerged culture fermentation of Australian raw materials. This paper reports an investigation of the conditions 
which lead to high yields of citric acid by the mutant strain 72-44 of $A$. niger. The media constituents were investigated in some experiments with single variables and in others with a factorial design with multiple variables. Millis, Trumpy \& Palmer (1963) showed that certain unsaturated lipids increased the yield of citric acid from cane sugar with mutant 72-44. Peanut oil, which is an active lipid in this system, was included in fermentation media to see whether this affected the optimal concentrations of other media constituents and to determine the concentrations of media constituents which give maximal increases in citric acid yield in the presence of oil.

\section{METHODS}

Organism. The mutant 72-44 of Aspergillus niger was used for all fermentations. The mutant was selected after ultraviolet irradiation of the spores of strain 72-4 of A. niger (ATCC 11414) as described by Millis $e$ al. (1963). Stock cultures were kept as spore suspensions freeze-dried in ampoules and working cultures on beer wort agar media.

Inoculum, fermentation techniques and determinations of fermentation products. The preparation of the spore inoculum, the conditions for shaken flask fermentations, the ion-exchange treatment of cane sugar used for media, the methods for the determination of sugar, citric acid and dry weight of mycelium, respectively, were as described by Millis et al. (1963).

Design of factorial experiments. For most experiments, three nutrients were investigated at three concentrations, making twenty-seven fermentations/experiment. This allowed the effect of each concentration of a nutrient to be estimated in nine fermentations containing three different concentrations of the other two nutrients.

Medium for single variable experiments with trace metals. The major nutrients of the fermentation medium in which the trace metals were varied were at the following concentrations (g./l.): 140 , ion-exchange purified cane sugar; $1 \cdot 0, \mathrm{KH}_{2} \mathrm{PO}_{4}$; $0 \cdot 25, \mathrm{MgSO}_{4} .7 \mathrm{H}_{2} \mathrm{O} ; \mathbf{1} \cdot \mathbf{8 7}, \mathrm{NH}_{4} \mathrm{NO}_{3}$. Trace metals, when not under test, were at the following concentrations (mg./l.): $\mathrm{Fe}^{2+}, 2 \cdot 0 ; \mathrm{Cu}^{2+}, 0 \cdot 3 ; \mathrm{Zn}^{2+}, 0 \cdot 1$. The medium was at $\mathrm{pH}$ 3.0. This medium will be referred to as medium $\mathbf{A}$.

Peanut oil. Refined and deodorized peanut oil (Kristal Brand, Marrickville Margarine Co., N.S.W., Australia), was added to appropriate media at $2 \%(\mathrm{v} / \mathrm{v})$ before the medium was autoclaved.

\section{RESULTS}

\section{Yield of citric acid}

If all the cane sugar in $100 \mathrm{ml}$. of medium were converted to citric acid, $14 \mathrm{~g}$. sucrose would yield $15 \cdot 7 \mathrm{~g}$. anhydrous citric acid. In high-yielding fermentations, however, between 1.0 and $1.5 \mathrm{~g}$. dry wt. mycelium/100 ml. is formed and this would use between 1.8 and $2.7 \mathrm{~g}$. sugar. Assuming all the sugar in the medium is utilized, between $11 \cdot 3$ and $12 \cdot 2 \mathrm{~g}$. sugar is, therefore, available for conversion to citric acid. This could theoretically yield $12 \cdot 7-13 \cdot 7 \mathrm{~g}$. anhydrous citric acid/100 ml. medium. In the presence of oil, Aspergillus niger mutant 72-44 has on ten occasions yielded as high as $13 \mathrm{~g}$. citric acid/100 ml. and on numerous occasions has yielded 12 $12.5 \mathrm{~g} . / 100 \mathrm{ml}$., but the average yield in shaken flask fermentations was $10-10.5 \mathrm{~g} . /$ $100 \mathrm{ml}$. under conditions which were favourable for citric acid accumulation. A yield 
of $10 \mathrm{~g}$. citric acid/100 ml. represents $71 \%$ conversion to citric acid of the sugar added to the medium but, of the sugar available after the growth requirements have been satisfied, $83 \%$ has been converted to acid. This is, however, a low estimate, since between 1.0 and $1.5 \mathrm{~g}$. sugar is unused at the end of a fermentation which yields $10 \mathrm{~g}$. citric acid/100 ml. In this paper, yields of citric acid above $9.5 \mathrm{~g} . / 100 \mathrm{ml}$. (that is, if more than $68 \%$ of sugar added to the medium is converted to citric acid) are considered high yields.
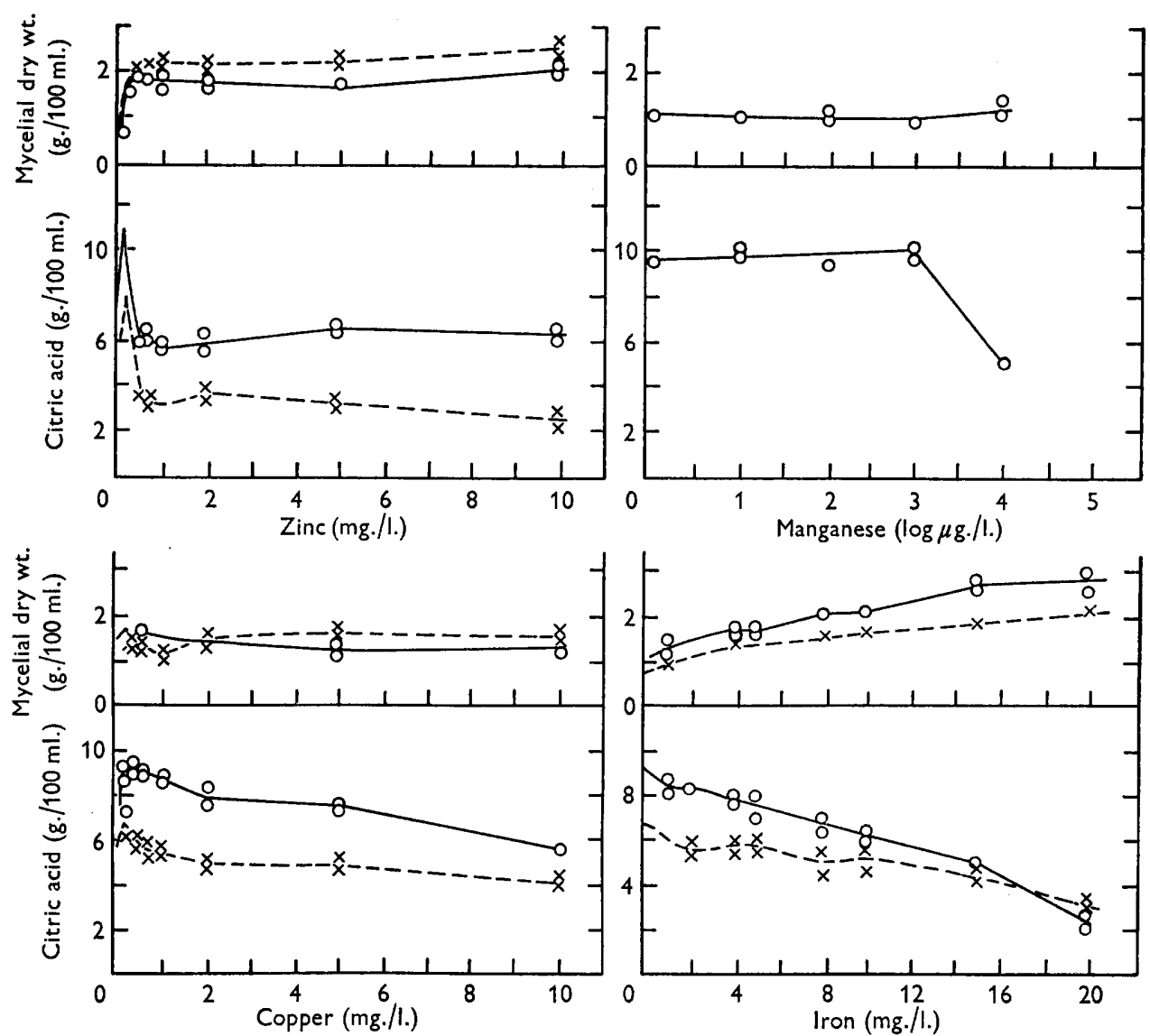

Fig. 1. Effect of trace metals on the yield of citric acid and the dry wt. of mycelium with Aspergillus niger mutant 72-44 grown in shaken culture: $\bigcirc-O$ results in the presence of $2 \%(v / v)$ peanut oil; $\times---\times$ results in the absence of peanut oil.

\section{Single variable experiments with trace metals and peanut oil}

The effect of each of the trace metals iron, copper and zinc was tested in medium A by changing the concentration of one of these metals while the other trace metals were held at the concentration of medium A. Media were dispensed in quadruplicate and peanut oil added to one half of these flasks. The effect of manganese was tested in the presence of oil. After 7 days, the yield of citric acid and the dry weight of mycelium were determined; the results are shown in Fig. 1. The most conspicuous feature of these fermentations was the high yield of citric acid at very low 
concentrations of zinc and the sensitivity of this yield to small additions of zinc. The fermentations also showed that Aspergillus niger mutant 72-44 gave considerably higher yields of citric acid at high concentrations of zinc, copper, iron and manganese as compared with the yields reported by Shu \& Johnson (1948) for the parent strain $\boldsymbol{A}$. niger 72-4. Like the parent strain, however, mutant 72-44, yielded citric acid best at low trace metal concentrations.

Figure 1 also shows that peanut oil greatly increased the yield of citric acid at all concentrations of metals, except at the highest concentrations of iron, but the concentrations of trace metals which gave the best yields of citric acid were the same in presence or in absence of oil. The oil had little effect on the dry-weight yield of mycelium, and at these concentrations of major nutrients, the dry-weight yield was little affected by trace metals, although there was a tendency for increased growth with high concentrations of iron.

\section{Factorial experiments with major nutrients}

To determine the best concentrations for citric acid accumulation, of the major nutrients, nitrogen, phosphate and magnesium, a factorial experiment involving twenty-seven media was designed to test three concentrations of each of the three nutrients. The concentrations chosen lay close to those already in use in medium $\mathbf{A}$, since these were known to give good yields of citric acid. The sugar and trace metal concentrations were as in medium A. A similar set of twenty-seven media was

Table 1. Effect of major nutrients and of peanut oil on yield of citric acid from Aspergillus niger mutant 72-44 in 9 days

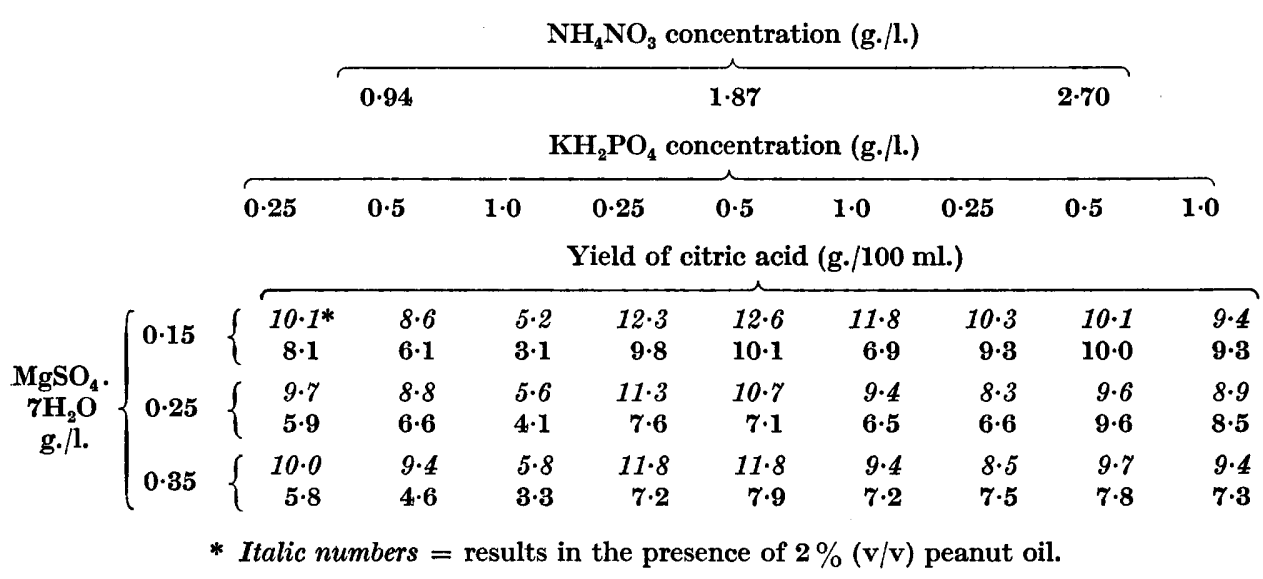

prepared and peanut oil added to each medium. The yield of citric acid from these fermentations at 9 days is shown in Table 1. As in the trace metal experiments, there was an improvement in citric acid yield in the presence of peanut oil at all nutrient concentrations tested. The mean citric acid yield in the presence of oil was $10.4 \mathrm{~g} . / 100 \mathrm{ml}$. compared with $7.9 \mathrm{~g} . / 100 \mathrm{ml}$. in its absence. The means of the yields from the three concentrations of each nutrient showed that the best yields in the presence of oil were obtained with (g./l.): $\mathrm{MgSO}_{4} .7 \mathrm{H}_{2} \mathrm{O}, 0.15 ; \mathrm{KH}_{2} \mathrm{PO}_{4}$, either 0.5 or $0.25 ; \mathrm{NH}_{4} \mathrm{NO}_{3}, \mathbf{1 . 8 7}$. There was also a definite interaction between nitrogen and 
phosphate; see Table 2. Clearly, increasing the phosphate depressed the yield of citric acid much more at the lowest nitrogen concentration than at high nitrogen concentrations, irrespective of the presence of peanut oil.

Table 2. Interaction between nitrogen and phosphorus affecting the yield of citric acid by Aspergillus niger mutant 72-44

\begin{tabular}{|c|c|c|c|c|c|c|}
\hline & \multicolumn{6}{|c|}{$\mathrm{NH}_{4} \mathrm{NO}_{3}$ concentration (g./l.) } \\
\hline & \multicolumn{2}{|c|}{0.94} & \multicolumn{2}{|c|}{1.87} & \multicolumn{2}{|c|}{2.70} \\
\hline & +Oil & - Oil & + Oil & - Oil & + Oil & - Oil \\
\hline $\mathrm{KH}_{2} \mathrm{PO}_{4}$ & \multicolumn{6}{|c|}{ Mean yield of citric acid (g./100 ml.) } \\
\hline $0 \cdot 25$ & $9 \cdot 8$ & $6 \cdot 6$ & 11 . & $8 \cdot 2$ & 9 & $7 \cdot 8$ \\
\hline 0.50 & 8.9 & $5 \cdot 8$ & $11 \cdot 3$ & 8.3 & $9 \cdot 8$ & $9 \cdot 1$ \\
\hline $1 \cdot 00$ & $5 \cdot 5$ & $3 \cdot 5$ & $10 \cdot 2$ & 6.9 & $9 \cdot 2$ & $8 \cdot 1$ \\
\hline
\end{tabular}

Table 3. Effects of major nutrients on yield of citric acid by Aspergillus niger, mutant 72-44 in the presence of peanut oil at 9 days

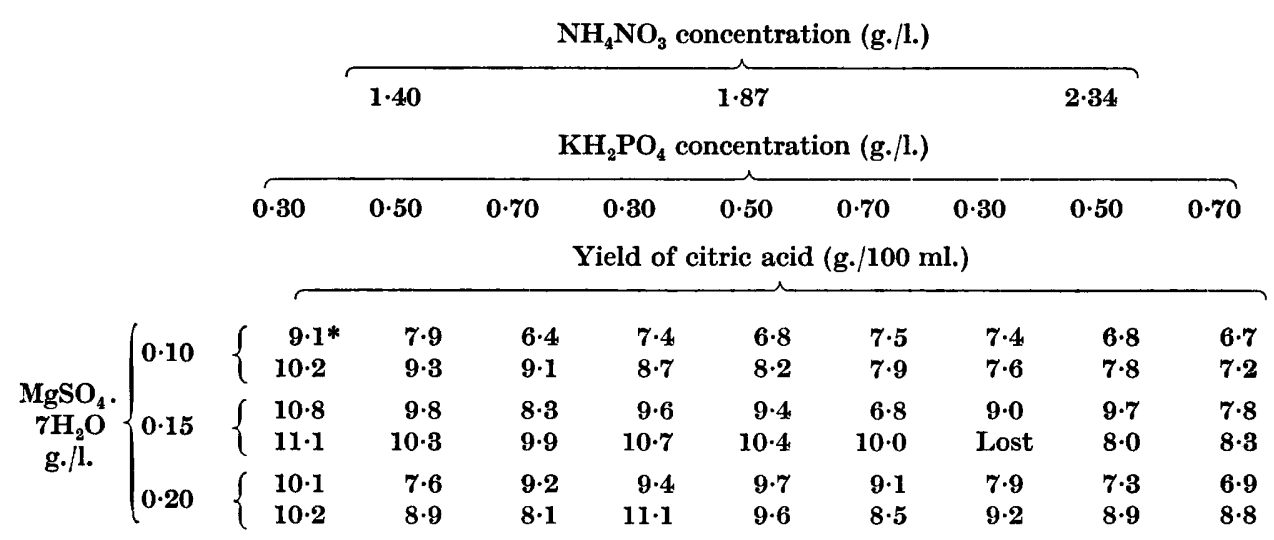

* Top figure of each pair represents value in one replicate experiment.

The mean dry wt. yield of mycelium of the twenty-seven fermentations in the presence of oil was $1.30 \mathrm{~g}$. $/ 100 \mathrm{ml}$. and was very similar in its absence, $1 \cdot 26 \mathrm{~g} . / 100 \mathrm{ml}$. The dry wt. yield of mycelium increased with increasing phosphate (1.04-1.54 g./ $100 \mathrm{ml}$. in the presence of oil, and 1.12-1.35 g./100 ml. in its absence), but otherwise the different concentrations of nutrients had little effect on mycelial dry weight.

In further factorial experiments, the three concentrations of nutrients were spaced equally apart and close to the concentrations which gave best yields in the first factorial experiment. All the fermentations were carried out in the presence of peanut oil, and to estimate the variability between factorial experiments at different times, the whole experiment was repeated with a newly-prepared inoculum and medium. The yields of citric acid from these two replicates after 9 days are shown in Table 3. Here, the upper figure shown in each treatment belongs to one experiment. These results were analysed statistically. As the concentrations of each nutrient were equally spaced on a linear scale, estimates were made of the linear and 
the quadratic trends associated with the variations in yield at these concentrations. The mean square due to error of the experiment was 0.589 , and the interactions between pairs of nutrients and between the three nutrients proved to be not significant. The difference between replicates was significant at the $0 \cdot 1 \%$ level, as were the linear effects of each of the major nutrients. Magnesium showed a quadratic effect significant at the $0.1 \%$ level. The main effects can be seen in Table 4 where the means of each level of each nutrient are shown together with the standard error (s.E.) and the s.E. of difference. The problem of variation of yield under supposedly similar conditions will be referred to in a later section.

Table 4. Means of the effects of major nutrients on yield of citric acid from Aspergillus niger mutant 72-44 in the presence of peanut oil

\begin{tabular}{|c|c|c|}
\hline $\begin{array}{l}\mathrm{MgSO}_{4} \cdot 7 \mathrm{H}_{2} \mathrm{O}(\mathrm{g} . / \mathrm{l} .) \\
\text { Citric acid (g./100 ml.) }\end{array}$ & $\begin{array}{l}0 \cdot 10 \\
7 \cdot 94\end{array}$ & $\begin{array}{l}0 \cdot 15 \\
9 \cdot 42\end{array}$ \\
\hline $\begin{array}{l}\mathrm{KH}_{2} \mathrm{PO}_{4}(\mathrm{~g} . / \mathrm{l} .) \\
\text { Citric acid (g./100 ml.) }\end{array}$ & $\begin{array}{l}0 \cdot 30 \\
9 \cdot 46\end{array}$ & $\begin{array}{l}0 \cdot 50 \\
8 \cdot 68\end{array}$ \\
\hline $\begin{array}{l}\mathrm{NH}_{4} \mathrm{NO}_{3}(\mathrm{~g} . / \mathrm{l} .) \\
\text { Citric acid (g./100 ml.) }\end{array}$ & $\begin{array}{l}1 \cdot 40 \\
9 \cdot 29\end{array}$ & $\begin{array}{l}1 \cdot 87 \\
8 \cdot 93\end{array}$ \\
\hline \multicolumn{3}{|c|}{$\left.\begin{array}{ll}\text { Mean of replicate } 1 & 8 \cdot 31 \\
\text { Mean of replicate } 2 & 9 \cdot 22\end{array}\right\}$ s.E.* $=0.15$} \\
\hline $\begin{array}{ll}\text { S.E. } & =0.18 \\
\text { S.E. (difference) } & =0.25\end{array}$ & & \\
\hline
\end{tabular}

The factorial experiments indicated that the yield of citric acid would be improved in the presence of peanut oil by using the following major nutrient concentrations (g./l.): $\mathrm{MgSO}_{4} .7 \mathrm{H}_{2} \mathrm{O}, 0.15 ; \mathrm{KH}_{2} \mathrm{PO}_{4}, 0.3 ; \mathrm{NH}_{4} \mathrm{NO}_{3}, 1 \cdot 4$. These nutrients, plus $14 \%(\mathrm{w} / \mathrm{v})$ ion exchange purified cane sugar and trace metals at the following concentrations (mg./l.): $\mathrm{Fe}^{2+2 \cdot 0} ; \mathrm{Cu}^{2+0.3}$; and $\mathrm{Zn}^{2+} 0 \cdot 1$, will be referred to as medium B subsequently.

\section{Factorial experiments with trace metals and oil}

In Fig. 1, the yield of citric acid in medium $A$ was reported for various concentrations of each of four trace metals. Factorial experiments were designed in which the major nutrients were as shown in medium $B$ and the concentrations of three trace metals (iron, zinc, copper) were varied simultaneously in the presence and absence of peanut oil. The results after 9 days of fermentation are summarized in Table 5.

An analysis of variance was done on the results of fermentations in the presence of peanut oil. The error was $\mathbf{0 \cdot 2 0 5}$, and the effect of different concentrations of copper and the interactions of zinc and copper and iron and copper were shown to be not significant. The effect of different concentrations of both zinc and iron were significant at the $0.1 \%$ level and the interaction of iron and zinc was significant at the $5 \%$ level. In the iron and zinc interaction, increasing zinc depressed the citric acid yield and increasing iron improved it but the improvement with increased iron was greatest when zinc was higher. These effects can be seen in the table of means listed in Table 6. 
The results of fermentations in the absence of peanut oil were not analysed statistically, but inspection of the means of the citric acid yield at the different trace metal concentrations shows similar trends to those just discussed for fermentations in the presence of peanut oil, excepting that there is no evidence of interaction between iron and zinc (Table 7).

Table 5. Effect of trace metals and peanut oil on the yield of citric acid from Aspergillus niger mutant 72-44 at 9 days

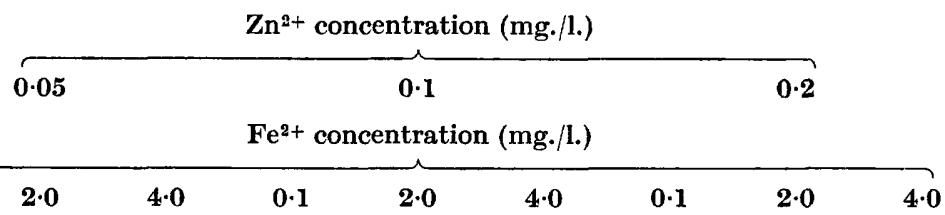

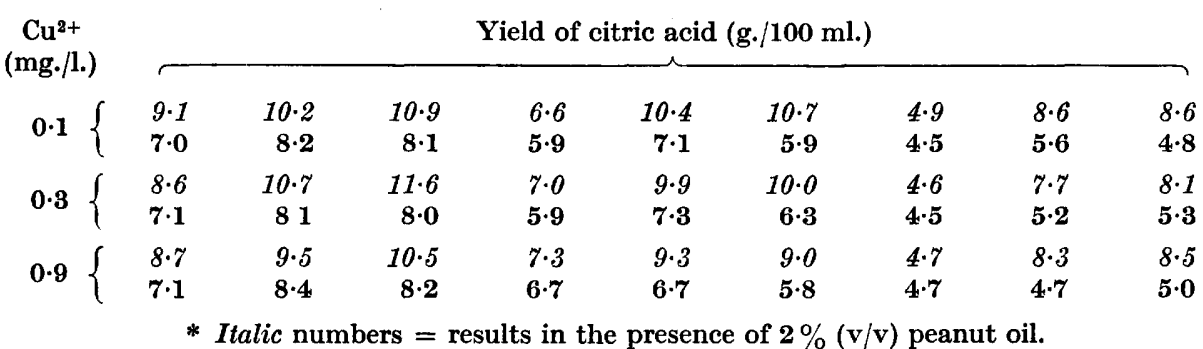

Table 6. Means of the effects of trace metals in the presence of peanut oil on yield of citric acid by Aspergillus niger mutant 72-44

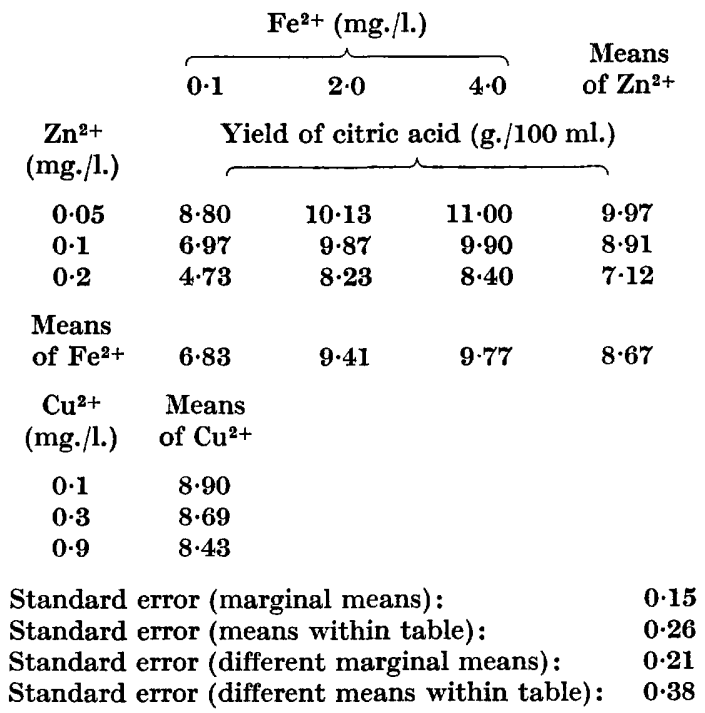

A comparison of Table 6 with Table 7 shows that peanut oil was most effective in increasing citric acid yield when the iron concentrations were highest (between 2 and $4 \mathrm{mg} . / 1$.). It was then decided to test the effect of even higher concentrations of iron in the presence and absence of oil. The highest concentration of copper in the 
factorial experiment was less than $1 \mathrm{mg} . / \mathrm{l}$. and this had no effect on yield. In the second factorial experiment, it was decided to increase the concentration of copper as well as that of iron to determine whether oil increased the citric acid yield at higher copper concentrations. Since the yield was so greatly depressed by zinc, fermentations were carried out with only two concentrations of zinc $(0.05,0.10$ mg./l.). The major nutrients were as in medium $B$ and the citric acid yields were estimated after fermentation for 9 days. These results are shown in Table 8.

Table 7. Means of the effect of trace metals in the absence of peanut oil on the yield of citric acid by Aspergillus niger mutant 72-44

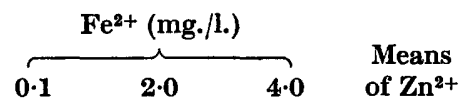

\begin{tabular}{|c|c|c|c|c|}
\hline $\mathrm{Zn}^{2+}$ & Yield & citri & (g. & nl.) \\
\hline 0.05 & $7 \cdot 1$ & $8 \cdot 2$ & $8 \cdot 1$ & 7.9 \\
\hline 0.1 & 6.2 & $7 \cdot 0$ & 6.0 & $6 \cdot 4$ \\
\hline $0 \cdot 2$ & $4 \cdot 6$ & $5 \cdot 2$ & $5 \cdot 0$ & $4 \cdot 8$ \\
\hline Means & & & & \\
\hline of $\mathrm{Fe}^{2+}$ & $6 \cdot 0$ & 6.8 & $6 \cdot 4$ & $6 \cdot 4$ \\
\hline$\underset{(\mathrm{mg} / \mathrm{l} .)}{\mathrm{Cu}^{2+}}$ & $\begin{array}{l}\text { Means } \\
\text { of } \mathrm{Cu}^{2+}\end{array}$ & & & \\
\hline $0 \cdot 1$ & 6.3 & & & \\
\hline $0 \cdot 3$ & 6.4 & & & \\
\hline 0.9 & $6 \cdot 4$ & & & \\
\hline
\end{tabular}

Table 8. Effect of trace metal concentrations and of peanut oil on the yield of citric acid from Aspergillus niger mutant 72-44 after 9 days

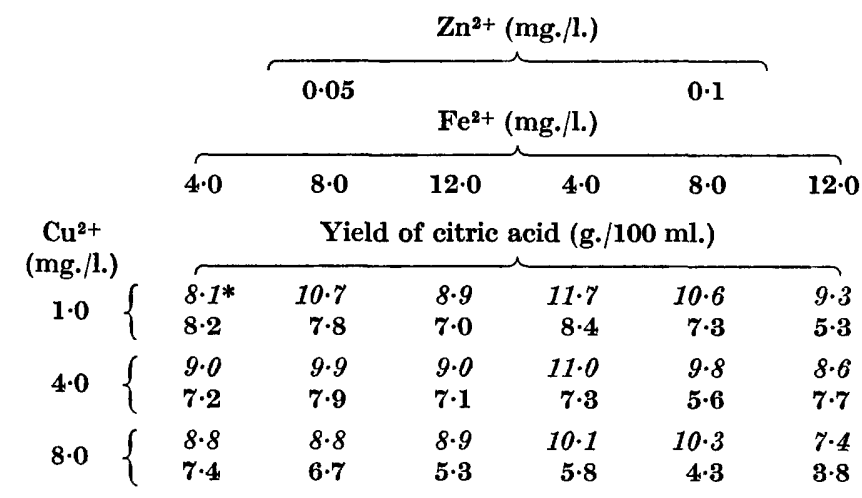

* Italic numbers $=$ results in presence of $2 \%(v / v)$ peanut oil.

An analysis of variance of the citric acid yields in the presence of oil, given in Table 8, indicated that at these higher concentrations of trace metals there was an interaction between zinc and iron significant at the $1 \%$ level. Neither of the other interactions, nor the effect of copper, was significant. The analysis of the means of the effect of iron and of zinc in the presence of peanut oil is shown in Table 9. The influence of peanut oil on the yield at various trace-metal concentrations can be seen 
in Table 10 which shows the mean of the effect of each metal concentration in the presence and absence of oil.

Oil improved the citric acid yield in all treatments. The yield was unaffected by $8 \mathrm{mg}$. copper/l. in the presence of oil but was depressed by copper above $4 \mathrm{mg}$./l. in the absence of oil. As in the presence of oil, an interaction between zinc and iron occurred in the absence of oil; the upper concentration of zinc depressed the citric

Table 9. Means of the effect of zinc and iron on the yield of citric acid by Aspergillus niger mutant 72-44 in the presence of peanut oil at 9 days

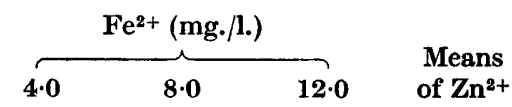

\begin{tabular}{|c|c|c|c|c|}
\hline \multirow{3}{*}{$\begin{array}{c}\begin{array}{c}\mathrm{Zn}^{2+} \\
(\mathrm{mg} \cdot / \mathrm{l} .)\end{array} \\
0.05 \\
0 \cdot 1\end{array}$} & \multicolumn{4}{|c|}{ Yield of citric acid (g./100 ml.) } \\
\hline & 8.63 & $9 \cdot 80$ & 8.93 & $9 \cdot 12$ \\
\hline & $10 \cdot 93$ & $10 \cdot 23$ & $8 \cdot 43$ & $9 \cdot 86$ \\
\hline \multicolumn{5}{|l|}{ Means } \\
\hline $\begin{array}{l}\text { s.e.* } 0.3 \\
\text { s.e. of dif }\end{array}$ & nce & & & \\
\hline
\end{tabular}

* s.E. = standard error.

Table 10. Means of effects of trace metals and of peanut oil on the yield of citric acid from Aspergillus niger mutant 72-44 at 9 days

\begin{tabular}{|c|c|c|c|c|c|c|c|c|}
\hline \multirow{3}{*}{$\begin{array}{c}\mathrm{Cu}^{2+} \\
\text { (mg./1.) } \\
1 \cdot 0\end{array}$} & +Oil & - Oil & & + Oil & - Oil & & + Oil & - Oil \\
\hline & \multicolumn{2}{|c|}{$\begin{array}{l}\text { Yield of citric acid } \\
(\mathrm{g} . / 100 \mathrm{ml} .)\end{array}$} & \multirow{2}{*}{$\begin{array}{c}\mathrm{Zn}^{2+} \\
\text { (mg./l.) } \\
0.05\end{array}$} & \multicolumn{2}{|c|}{$\begin{array}{l}\text { Yield of citric acid } \\
\quad(\mathrm{g} . / 100 \mathrm{ml} .)\end{array}$} & \multirow{2}{*}{$\begin{array}{c}\mathrm{Fe}^{2+} \\
\text { (mg./l.) } \\
4.0\end{array}$} & \multicolumn{2}{|c|}{$\begin{array}{l}\text { Yield of citric acid } \\
\quad \text { (g. } / 100 \mathrm{ml} .)\end{array}$} \\
\hline & $9 \cdot 80$ & $7 \cdot 33$ & & $9 \cdot 12$ & $7 \cdot 18$ & & 9.78 & $7 \cdot 38$ \\
\hline $4 \cdot 0$ & 9.55 & $7 \cdot 13$ & $0 \cdot 10$ & $9 \cdot 86$ & $6 \cdot 17$ & $8 \cdot 0$ & $10 \cdot 02$ & $6 \cdot 60$ \\
\hline 8.0 & 9.05 & 5.55 & . & . & . & $12 \cdot 0$ & $8 \cdot 68$ & $6 \cdot 03$ \\
\hline
\end{tabular}

acid yield markedly when iron was greater than $4 \mathrm{mg}$./l.; at the lower concentrations of zinc higher amounts of iron could be tolerated. At the higher zinc concentration $(0.10 \mathrm{mg} . / \mathrm{l}$.$) , oil improved the citric acid yield at all concentrations of iron to a$ greater extent than when zinc was at the lower concentration (0.05 mg./1.). At 8-12 mg. iron/l., 2-3 mg. more citric acid /100 ml. were formed in the presence of oil than in its absence, but the actual citric acid yield decreased when iron was increased from 8 to $12 \mathrm{mg}$./l., even in the presence of oil.

\section{Factorial experiment to test for interaction between major nutrients and trace metals}

The previous experiments indicate that there were interactions between major nutrients and between trace metals influencing the yield of citric acid. It is also clear that zinc is a particularly critical metal for Aspergillus niger mutant 72-44. 
It was thought possible that major nutrients and trace metals may also interact, and if so, that this suggests changes in major nutrients which would improve the tolerance of the mutant to trace metals, and in particular to zinc. This possibility was investigated in a factorial experiment with six media components each at two concentrations. The experiment was designed as a half replicate of the full factorial experiment, and was arranged in two randomized blocks, each of sixteen media. The concentration chosen lay on either side of those found optimal in the earlier factorial experiments. Peanut oil was added to all media and the yields of citric acid estimated after fermentation for 9 days. Statistical analysis of the citric acid yields indicated that the block effect and all interactions except that of $\mathrm{NH}_{4} \mathrm{NO}_{3}$ with iron were not significant. With the nitrogen and iron interaction, the higher concentration of nitrogen combined with the higher concentration of iron decreased the citric acid yield, whereas with the lower concentration of nitrogen, increasing the amount of iron did not depress the citric acid yield. The effect of $\mathrm{KH}_{2} \mathrm{PO}_{4}$ was significant at the

Table 11. Effect of six components of the growth medium on the yield of citric acid by Aspergillus niger mutant 72-44 in the presence of peanut oil at 9 days

\begin{tabular}{|c|c|c|c|}
\hline $\begin{array}{l}\text { Medium } \\
\text { component }\end{array}$ & $\begin{array}{l}\text { Mean yield } \\
\text { citric acid } \\
(\mathrm{g} . / 100 \mathrm{ml} .)\end{array}$ & $\begin{array}{c}\text { Standard } \\
\text { error of } \\
\text { difference }\end{array}$ & Significance \\
\hline \multicolumn{4}{|l|}{$\begin{array}{c}\mathrm{MgSO}_{4} \cdot 7 \mathrm{H}_{2} \mathrm{O} \\
\text { (g./l.) }\end{array}$} \\
\hline $0 \cdot 1$ & $9 \cdot 44$ & 0.263 & None \\
\hline $0 \cdot 2$ & $9 \cdot 93$ & & \\
\hline \multicolumn{4}{|l|}{$\begin{array}{c}\mathrm{KH}_{2} \mathrm{PO}_{4} \\
(\mathrm{~g} . / \mathrm{l} .)\end{array}$} \\
\hline $0 \cdot 25$ & $9 \cdot 94$ & 0.215 & $5 \%$ \\
\hline 0.5 & $9 \cdot 42$ & & \\
\hline \multicolumn{4}{|l|}{$\underset{(\mathrm{mg} . / \mathrm{l} .)}{\mathrm{Zn}^{2+}}$} \\
\hline 0.05 & $10 \cdot 10$ & $0 \cdot 263$ & $1 \%$ \\
\hline 0.15 & $9 \cdot 27$ & & \\
\hline \multicolumn{4}{|l|}{$\underset{(\mathrm{mg} \cdot / \mathrm{l} .)}{\mathrm{Cu}^{2+}}$} \\
\hline $1 \cdot 0$ & $9 \cdot 88$ & 0.263 & None \\
\hline $4 \cdot 0$ & $9 \cdot 48$ & & \\
\hline
\end{tabular}

Table 12. Interaction of $\mathrm{NH}_{4} \mathrm{NO}_{3}$ and iron on yield of citric acid by Aspergillus niger mutant 72-44

\begin{tabular}{|c|c|c|c|}
\hline & \multicolumn{2}{|c|}{$\mathrm{NH}_{4} \mathrm{NO}_{3}(\mathrm{~g} . / 1)}$. & \multirow{2}{*}{$\begin{array}{c}\text { Means of } \\
\mathrm{Fe}^{2+}\end{array}$} \\
\hline & $1 \cdot 2$ & $2 \cdot 0$ & \\
\hline$\underset{(\mathrm{mg} . / 1 .)}{\mathrm{Fe}^{2+}}$ & \multicolumn{3}{|c|}{ Yield of citric acid (g./100 ml.) } \\
\hline $\begin{array}{r}6 \cdot 0 \\
10 \cdot 0\end{array}$ & $\begin{array}{r}9 \cdot 81 \\
10 \cdot 06\end{array}$ & $\begin{array}{l}9 \cdot 99 \\
8 \cdot 87\end{array}$ & $\begin{array}{l}9 \cdot 90 \\
9 \cdot 47\end{array}$ \\
\hline $\begin{array}{l}\text { Means of } \\
\mathrm{NH}_{4} \mathrm{NO}_{3}\end{array}$ & $9 \cdot 93$ & $9 \cdot 43$ & $9 \cdot 68$ \\
\hline
\end{tabular}


$5 \%$ level, while the effect of zinc was significant at the $1 \%$ level. Both of these nutrients gave better citric acid yields at the lower concentrations. These results are summarized in Tables 11 and 12.

\section{Variation in citric acid yield}

Within any one factorial experiment, there was no doubt that the major nutrients significantly affected the yield of citric acid. The concentrations of nutrients used in medium $\mathbf{B}$ were always superior to those used in medium $\mathbf{A}$ in the factorial experiments. Later, on several different occasions, medium $\mathbf{A}$ and medium $\mathbf{B}$ were compared in the same experiment and there was no consistent difference in citric acid yield; sometimes medium A was even superior to medium B. This can only mean that unrecognized and uncontrolled factors can so affect citric acid yield that, if these factors are favourable to high yields, then the nutrient differences in the two media are not significant. If the uncontrolled factors are unfavourable to high citric acid yields then medium $\mathbf{B}$ is superior to medium $\mathbf{A}$.

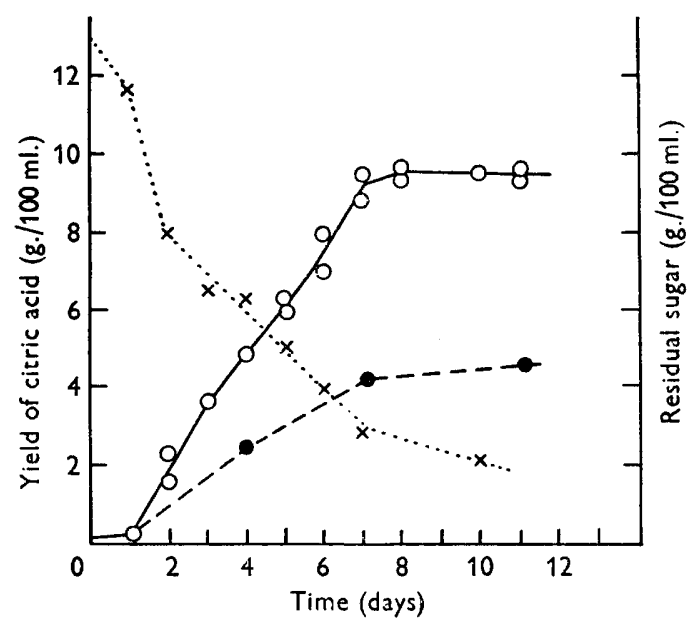

Fig. 2. Rate of citric acid production and sugar utilization by Aspergillus niger mutant $72-44$ in medium A. $\bigcirc-O$ citric acid in the presence of $2 \%(v / v)$ peanut oil; citric acid in the absence of peanut oil; $x---x$ residual sugar in presence of $2 \%(v / v)$ peanut oil.

During the investigation, three different dried cultures were used to prepare inocula and different batches of sugar were used. It was possible that these factors were responsible for some of the variation; fermentations were therefore made in medium $\mathbf{A}$ and medium $\mathbf{B}$ to test this possibility. No significant differences were found between the citric acid yields from the two media when tested for all combinations of sugar batch and inoculum source. It should be pointed out, however, that this variability was from $9 \cdot 5$ to $13 \mathrm{~g}$. citric acid/100 ml., that is, variability between good yields and yields very close to what is, theoretically, possible.

\section{Sugar utilization}

With a yield of citric acid of $10 \cdot 0-10.5 \mathrm{~g} . / 100 \mathrm{ml}$., there was residual sugar of $1 \cdot 0$ and $1.5 \mathrm{~g} . / 100 \mathrm{ml}$., which was decreased to less than $0.2 \mathrm{~g} . / 100 \mathrm{ml}$. as the citric acid 
yield increased to $13 \mathrm{~g}$. $/ 100 \mathrm{ml}$. Fermentations in the presence of oil had a faster rate of sugar utilization and a lower residual sugar than those without oil. In Fig. 2, the rate of citric acid accumulation and sugar utilization is shown in the presence of oil, as compared with the rate of citric acid accumulation in the absence of oil.

\section{Purity of fermentation products}

Although all citric acid yields reported here are calculated from total titratable acidity, frequent tests were made to ensure that only citric acid was being produced. Spot tests were made for oxalic acid (Feigl, 1960), chromatograms were run on culture fluids (Millis et al. 1963) and citric acid was estimated colorimetrically by the method of Marier \& Boulet (1958). In these tests, no acid other than citric was detected, and the agreement between the colorimetric and titratable-acidity estimations varied between 98 and $103 \%$. These tests were made on culture fluids containing peanut oil, oleic acid and a high content of trace metals as well as with media with low trace metal content and no lipid present.

\section{DISCUSSION}

Accumulation of large amounts of citric acid is the result of metabolic malfunction of Aspergillus niger in a medium of low $\mathrm{pH}$ value with a high sugar content and carefully controlled concentrations of other nutrients; and the amount of growth must be limited. This has been clearly shown in these investigations where the best yields of citric acid were always associated with mycelial pellets about $0.5 \mathrm{~mm}$. in diameter suspended in a culture medium of very low viscosity, virtually free from mycelial fragments and with less than $1 \mathrm{~g}$. dry wt. mycelium/100 ml.

Multiple nutritional deficiencies can cause limited growth; the nitrogen, phosphorus, zinc and iron concentrations are particularly important. At very low concentrations of zinc, growth was severely limited, but once the zinc content was increased above $\mathbf{0 . 1} \mathrm{mg}$./l., further increases have no effect. At higher zinc concentrations, iron, nitrogen or phosphorus then limited growth. Medium B had a low nitrogen and phosphorus content and this contributed to the growth-limiting effect of this medium.

Although growth must be limited, this of itself is not sufficient to give high yields of citric acid. Low concentrations of certain trace metals are also required. With this mutant 72-44 of Aspergillus niger, citric acid yield is particularly sensitive to zinc but less so to iron, copper and manganese. The interaction between iron and zinc offers some opportunity of improving tolerance of zinc, since higher concentrations of zinc do not depress citric acid yield as greatly when combined with higher concentrations of iron. In addition, higher concentrations of iron do not depress the citric acid yield when the concentration of zinc is very low. The interaction of iron and nitrogen also offers a means of overcoming the depressing effect of high iron concentration. A high iron concentration does not decrease the citric acid yield if the nitrogen concentration is low.

The addition of peanut oil to the fermentation medium has shown an improvement of 2-3 g. citric acid/100 ml. with a wide variety of media. Oil improves the yield most markedly when trace metal concentrations are high, particularly iron and copper. Low phosphorus and high magnesium media also respond well to oil. 
At $0.05 \mathrm{mg}$. zinc/l., yields of 10-11 g. citric acid/100 ml. were obtained at $20 \mathrm{mg}$. iron/l. When iron was at $0.01 \mathrm{mg} . / \mathrm{l}$. and zinc greater than $0.05 \mathrm{mg} . / \mathrm{l}$., oil gave no improvement. Oil was not effective with $2 \cdot 7$ g. or more $\mathrm{NH}_{4} \mathrm{NO}_{3} /$ l. (yields in these media were high in presence and in absence of oil).

The variability of citric acid yield shown in this study when every care was taken to standardize procedures indicates that all factors which affect this yield are not yet known. The diversity of known individual factors and interrelated factors which affect citric acid yield make it scarcely surprising that no one medium emerges clearly as being optimal for citric acid production. This work does, however, allow some generalizations to be made about the behaviour of Aspergillus niger mutant 72-44. This mutant is more tolerant of higher concentrations of trace metals than is the parent, but it yields citric acid best at low concentrations of trace metals. Zinc is the most critical single medium component. Mutant 72-44 will yield citric acid well in the presence of oil despite a relatively high content of iron and copper, as long as a major nutrient like nitrogen or phosphorus is low. It seems then, that several different nutrient deficiencies can lead to the accumulation of citric acid. If a natural crude sugar is to be used as a substrate for this fermentation, then it would be profitable to add peanut oil to all fermentations and to select samples of crude sugar as low as possible in nitrogen and phosphorus where trace metal deficiencies are not so critical, and to see that there is sufficient iron present to minimize the depressing effect of zinc on citric acid yield. The proper explanation of the highly complex interactions shown in this study must await a full biochemical investigation.

We are greatly indebted to Mr W. B. Hall (Division of Mathematical Statistics, C.S.I.R.O., Parkville, Victoria, Australia), for the planning of factorial experiments and their statistical analysis. The technical assistance of Mr M. Grinbergs and Mr R. Bearlin is gratefully acknowledged. Grants from the National Health and Medical Research Council of Australia and the University of Melbourne Research Fund provided financial support for one of us (B.H.T.).

\section{REFERENCES}

Feigl, F. (1960). Spot Tests in Organic Analysis, p. 385, 6th ed. London: Elsevier Publ. Co.

Foster, J. W. (1949). Chemical Activities of Fungi, p. 378. New York: Academic Press, Inc.

Johnson, M. J. (1954). The citric acid fermentation. In Industrial Fermentations, Vol. I, p. 420. Ed. L. A. Underkofler and R. J. Hickey. New York: Chemical Publishing Co., Inc.

Marier, J. R. \& Boulet, M. (1958). Direct determination of citric acid in milk with an improved pyridine-acetic anhydride method. J. Dairy Sci. 41, 1683.

Millis, N. F., Trumpy, B. H. \& Palmer, B. M. (1963). The effect of lipids on citric acid production by an Aspergillus niger mutant. J. gen. Microbiol. 30, 365.

Perlman, D. \& Sir, C. J. (1960). Fungal synthesis of citric, fumaric and itaconic acids. Prog. indust. Microbiol. 2, 167.

Shu, P. \& Johnson, M. J. (1948). The interdependence of medium constituents in citric acid production by submerged fermentation. J. Bact. 56, 577 . 